\title{
Hegel ante la Doctrina de la ciencia ${ }^{1}$
}

\author{
REINHARD LAUTH $\dagger$ \\ Ludwig Maximiliam Universität, Munich
}

Viene durando ya casi dos siglos que la filosofía no ha sido capaz de liberarse de una apreciación errónea que Hegel introdujo en ella. Me refiero a aquel enjuiciamiento equivocado según el cual la Doctrina de la ciencia de Fichte no ha de representar otra cosa que un estadio preliminar superado para el sistema de Hegel. Con esta valoración iba y sigue yendo unida la convicción de que es legítimo compilar la Doctrina de la ciencia junto con la doctrina de la identidad de Schelling y el idealismo absoluto de Hegel dentro del mismo género de filosofía. Los adversarios han sacado de ahí la conclusión de que a la Doctrina de la ciencia hay que incluirla juntamente con estos otros sistemas en la misma condena. Podrían aducirse cuantos ejemplos se quisiera. Doy uno solo, pero muy significativo. Nadie menos que Ernest Hello escribió en la segunda mitad del siglo pasado:

"Maintenant que Schelling est mort, [...] que fait l'erreur? où en est-elle? [...] Prenez un microscope. Voyez-vous dans les bas-fonds se remuer ces infiniment petits? Ce sont de petits bons-hommes qui ne savent plus même lire. [...] Ils parlent, mais ils ne disent rien, on ne peut même plus ni caractériser ni nommer leur erreur. Ils sont entrés dans de domaine du je ne sais quoi. Trois hommes de génie avaient pourtant éclaté en Allemagne. Fichte, Schelling, Hégel avaient parlé. [...] ils n'ont pas trouve la verité: soit; mais comment nònt-ils pas laissé une école monumentale

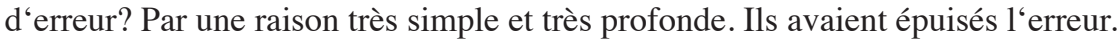
Hegel a condensé $l^{\prime}$ erreur; il l'a systématisée, il l'a proférée, si je puis ainsi parler,

1 Este texto es la traducción del "Prólogo" que Reinhard Lauth (*1919 Oberhausen - †2007 Múnich) escribió a su libro: Hegel vor der Wissenchaftslehre. Akademie der Wissenschaften und der Literatur, Mainz / Franz Steiner Verlag Wiesbaden GmbH, Stuttgart, 1987. Cfr. "Vorwort", pp. 5-7. Próxima edición de la traducción al español, Hegel ante la Doctrina de la ciencia, a cargo del Instituto Filosófico Reinhard Lauth. 
tout entière en un mot: [...] l'Être et le Néant sont identiques“"2.

Aunque hoy, tras largas confrontaciones entre los conocedores de las filosofías schellinguiana y fichteana con los partidarios de Hegel, se confiesa por lo general que estas filosofías no quedan refutadas ni superadas por la de Hegel, sin embargo se está muy lejos de sacar las consecuencias a partir de este hecho. La Doctrina de la ciencia y el idealismo absoluto se siguen tratando por lo general bajo el nombre, que filosóficamente no dice nada, de "idealismo alemán"; y aun cuando uno se avergüenza ya de repetir la fórmula de Kroner: "de Kant a Hegel", sin embargo, interiormente uno no se ha liberado en modo alguno de compilar la filosofía transcendental y el idealismo absoluto, que se oponen mutuamente como agua y fuego, conjuntamente como "idealismo“. En correspondencia con la falta de dignidad de nuestro siglo, temeroso de todo posicionamiento, se prefiere preguntar: "¿Kant o Hegel?", aunque esta alternativa no hace más que delatar dónde se ha quedado uno.

La culpa de esta situación grotesca la tiene sobre todo la impotencia filosófica, pero también el oportunismo de muchos filósofos alemanes de profesión, y por encima de todo, el oportunismo de aquellos de entre éstos que, en este siglo y en el pasado, se han dado en llamar "dirigentes". Hello tiene razón: "Ils sont entrés dans le domaine du je ne sais quoi." Es ocioso seguir investigando aquí la pregunta de dónde radica la causa última de ello, pues en este trabajo no se trata de ella, sino del estadio de desarrollo en el que la filosofía se encuentra de hecho. ${ }^{3}$

Hacia el final de su vida, Kant anotó:

"Todas las elaboraciones filosóficas no merecen el nombre de una filosofía como ciencia si no se establecen como vinculadas en un sistema. Filosofar fragmentariamente significa sólo hacer ensayos en el pensamiento con la razón, ensayos en los que poca confianza se puede depositar mientras no se les haya podido asignar su posición y su parentesco determinados con los otros mediante la clasificación del conjunto"4.

Si la filosofía sólo puede realizarse como sistema global, entonces tenemos toda la razón para observar con una atención máxima los pocos intentos de este tipo, que pueden contarse con ambas manos, para examinarlos y para pensarlos hasta el fondo con todo nuestro esfuerzo espiritual. En lugar de repetir clichés

2 Ernest Hello: L'Homme, París 1936, pp. 136/37.

3 Siempre quedará como un hecho curioso que Fichte haya conocido en Francia una comprensión y una valoración totalmente distintas que en Alemania. En la patria del filósofo, apenas se puede equiparar a nadie con intérpretes de la talla de un X. Léon, un M. Gueroult o un A. Philonenko

4 Opus potumum, Akad.-Ausg., vol. XXI, p. 524. 
trillados hasta el asco como "confusión psicológica", "absolutización del yo", "idealismo subjetivo", "filosofía de reflexión", con los que desde Jacobi, Reinhold y Hegel se ha pretendido ponerse a la altura de la Doctrina de la ciencia, tiene que aparecer una investigación fundamental. Las doctrinas del sistema de la filosofía transcendental tienen que compararse y medirse cada una de ellas con las del idealismo absoluto. Eso es lo que he tratado de hacer en los capítulos que siguen, y el resultado cae en efecto a favor de la filosofía transcendental y del sistema fichteano, cuya rigurosa fundamentación epistemológica les asegura un status totalmente distinto que a la metafísica especulativa. La filosofía transcendental es idealismo metódico, pero en modo alguno idealismo metafísico. Merced a su principio fundamental es toto coelo distinta de toda mera metafísica, por mucho que ésta última, en algunos de sus representantes, pretenda hacerse pasar por aparentemente transcendental. Justamente porque esto se sigue oscureciendo aún una y otra vez con el etiquetamiento, que nada dice, de "idealismo absoluto", siempre que ha sido necesario he llevado a cabo mis investigaciones con una determinación crítica sin transigencias. Mi tarea ha sido traer al idealismo hegeliano ante la Doctrina de la ciencia inabreviada e infalseada, y no ante aquel fantasma que, conforme a la medida de los filósofos "dirigentes" anteriormente aludidos, se sigue saldando por lo general a toda prisa y con poco valor entre los receptores.

La Doctrina de la ciencia no ha sido aún refutada, ni siquiera en la forma incompleta en la que se hallaba cuando, en 1801, Hegel y Schelling pretendieron poder triunfar sobre ella. Ni la crítica a ella ni lo que se le opuso como filosofía verdadera pueden resistir un examen minucioso. Por el contrario, hoy puede decirse con total seguridad que el sistema que Hegel expuso es insostenible. Ya sólo esta circunstancia es motivo suficiente para prestarle la máxima atención al sistema transcendental, sobre todo en una época como la nuestra, que carece de fuerza sistemática y que amenaza con perderse por completo en investigaciones parciales e individuales.

Entiéndase bien que estoy hablando del sistema fundamental, y no de los desarrollos en disciplinas filosóficas particulares. En ellas, los tiempos sucesivos han avanzado en algunos ámbitos parciales, y en ellas queda aún inmensurablemente mucho por hacer. Sin embargo, frente a los "petits bonshommes" de los que habla Hello, hay que decir por otra parte que ya se ha hecho mucho más de lo que por lo general uno se da cuenta. Pero esto sólo puede enjuiciarse suficientemente desde la visión del sistema global y de la conexión de lo particular con éste.

Ciertamente, el vuelo de altura sin parangón de la filosofía transcendental convierte a Kant y a Fichte en los filósofos del período clásico más difíciles de entender. Por eso hay que contar con ello, y habrá que aceptar que tendrán el mismo destino que Platón y Aristóteles, cuyas filosofías se vieron desplazadas 
en lo sucesivo en la amplia opinión pública por otras filosofías que son más cómodas por ser más superficiales. Pero eso no pudo ni podrá impedir que los conocimientos de más profundo alcance de esta filosofía sigan trabajando como fermento en todo trabajo futuro de pensamiento.

En vista del empobrecimiento a nivel mundial en cuanto a pensamiento sistemático, del que los callejones sin salida adonde conduce el sistema de Hegel no son los últimos culpables, espero que el presente trabajo les resulte oportuno a todos aquellos cuyo interés siga siendo verdaderamente la filosofía en cuanto tal, y eso significa: el sistema global concebible. Que pueda ser publicado al mismo tiempo en Alemania, Francia y Japón, he de agradecerlo a esfuerzos análogos de filósofos transcendentales sobresalientes en estos y otros países. 